\title{
BIOSENSORS' PREPARATION TO BE USED FOR ENTRAPMENT METHOD WITH COPOLYMERS POLYANILINE DERIVATIVES
}

\author{
C. O. SANCHEZ ${ }^{1 *}$, A. ISLA ${ }^{1}$, C. BUSTOS ${ }^{1}, F . D I A Z^{2}, N . G^{2} A T I C A^{3}$ \\ 1. Instituto de Quimica, Facultad de Ciencias, Universidad Austral de Chile, Avda. Las Encinas 220, Isla Teja, Valdivia, Chile. \\ 2. Departamento de Química Orgánica, Facultad de Química, Universidad Católica de Chile, Avda. Vicuña Mackenna 4860, Macul-Santiago, Chile \\ 3. Departamento de Polímeros, Facultad de Ciencias, Universidad de Concepción, Edmundo Larenas 129, Concepción, Chile \\ (Received: September 14, 2009 - Accepted: February 1, 2010)
}

\begin{abstract}
The entrapment method was used to prepare electrochemical biosensors. Using controlled potential method, copolymers were synthesized between aniline y sulfonated-anilines in aqueous media at pH 4.9 on Platinum disc. The copolymers were characterized by elemental analysis and spectroscopy. Glucose-oxidase was entrapped in the electropolymerization process, at $\mathrm{pH} 4.9$ in aqueous media. The copolymers modified electrodes and copolymer/enzyme were studied as working electrodes for the oxidation of different $\mathrm{H}_{2} \mathrm{O}_{2}$ concentrations and indirect D-glucose quantification at pH 7, using controlled potential and the cyclic voltammetry methods $(\mathrm{CV})$ correspondingly. A linear relationship between the hydrogen peroxide (or D-glucose) concentration and the electrochemical response was obtained at $\mathrm{pH}$ 7. The modified-electrodes displayed a fast time of current response, limited by the cycle numbers of the cyclic voltammetry, $232 \mathrm{~s}$, and enough stability to allow for the measurements to be taken after several days.
\end{abstract}

Keywords: Copolymers, Electrochemistry, enzyme, biosensor

\section{INTRODUCTION}

Polymers have been used in the preparation of biosensors, which can quantify the hydrogen peroxide generated in the oxidation of sugars, the reaction is catalyzed by oxidase-type enzymes ${ }^{1-3}$. The hydrogen peroxide formed in the reaction of oxidation can be quantified by electrochemical methods and its amount is directly related with the sugar quantity. The immovilized enzymes in polypirrol have been carried out by several methods such as physical adsorption, covalent union, entrapment and electrochemical doping $^{2-9}$. The entrapment method involves to capture the enzyme during the polymer electrosynthesis process, from a monomeric solution that contains the enzyme. This method presents the following requirements, the process of polymerization should be carried out in aqueous medium and $\mathrm{pH}$ that no deactivate or denature the enzyme, the monomer should be soluble in aqueous media and it's desirable that the polymer exhibits conductivity properties. Because to the previous requirements, polyaniline and polyaniline derivatives have not been studied enough using the entrapment method because: i) the monomer is practically insoluble at neutral $\mathrm{pH}$ in aqueous medium, ii) the polymer prepared at $\mathrm{pH}>3.5$, is non-conducting, and at $\mathrm{pH}<3$ the enzyme is de-naturalized ${ }^{9}$, iii) the polymer can be electrochemically synthesized in strong acid medium, nevertheless, the acid absorbed in the resulting polymer denatures the enzyme ${ }^{4,9,12-14}$. Therefore, the entrapment method using aniline as monomer can not be used. We solved this problem by preparing copolymers using aniline derivatives. The copolymers should be electroactive and insoluble at $\mathrm{pH} 5-7$, it is desirable they be electrically conductive and the co-monomers should be soluble in an aqueous media in the range of $\mathrm{pH} 5-7$. After an extensive review of published data, we postulated that the co-monomers of aniline derivatives 2-amino phenyl sulfonic acid and 3-amino phenyl sulfonic acid can be used to inmovilize enzymes in the polymerization process.

The goal of this paper is to prepare biosensors using the entrapment method with the copolymers between aniline and 2-amino phenyl sulfonic acid and 3-aminophenyl sulfonic acid. The enzyme (glucose-oxidase) entrapment was possible by the electropolymerization process in aqueous medium ( $\mathrm{pH} 4.9$ ) without denaturing the enzyme. The behavior of the obtained biosensors in relationship to electrochemical response of hydrogen peroxide and D-glucose in aqueous media at $\mathrm{pH} 7$ are also reported.

To study the bio-electrodes, the electrodes Pt/copolymers and Platinum disc were analized as working electrodes for the oxidation of $\mathrm{H}_{2} \mathrm{O}_{2}$ solutions at different concentrations, using cyclic voltammetry and the controlled potential electrochemical method.

\section{EXPERIMENTAL}

Physical measurements

Potenciodynamic measurements, cyclic voltammetry and electropolymerizations were conducted with a Voltametric Analyzer Bioanalytical System Inc., model C-3, in three-electrode cells, using platinum disc $\left(7.07 \mathrm{~mm}^{2}\right)$ as working electrode, a $\mathrm{Ag} / \mathrm{AgCl}$ as reference electrode, and a coil platinum wire $(0.5 \mathrm{~mm}$ diameter $)$ as an auxiliary electrode. Working electrodes were polished using aluminum oxide paste to obtain shiny surfaces prior to copolymer depositions. Sufficient amount of polymers were obtained to achieve the elemental analysis using $4-\mathrm{cm}^{2}$ platinum sheets as working electrodes. Then, the films were removed from electrodes by solubilization with acetone and acetonitrile, and finally the solvent was eliminated under vacuum at $40-50^{\circ}$.

The copolymer's composition and the functional groups were determined by elemental analysis and FT-IR spectroscopy. Elemental analysis $(\mathrm{C}, \mathrm{H}, \mathrm{N}$, S) was performed using an EA-1108, Fisons Elemental Analyzer. IR spectra were recorded on a Nicolet FT-IR Nexus spectrophotometer on KBr pellets. The UV-Vis spectra were recorded in solution using $0.03121 \mathrm{M}$ triethylamine prepared in dimethylformamide (DMF) as dissolvent, in a 1-cm long cell at room temperature $\left(20^{\circ}\right)$. The UV-Vis spectra were registered with a UNICAM UV 500 equipment.

\section{Reagents}

Reagent grade $\mathrm{KH}_{2} \mathrm{PO}_{4}$ (Merck), DMF (J. T. Baker), Triethylamine (Merck), sodium chloride (Merck), D-b-glucose (Aldrich), Glucose-oxidase (GOx) type II, from Aspergillus niger (Sigma-Aldrich), aniline-2-sulfonic acid and aniline-3-sulfonic acid (Aldrich) and hydrogen peroxide (Arquimed) were used without further purification. Aniline (Aldrich) was purified by distillation. $0.1 \mathrm{M}$. Stock glucose solution was prepared in $0.1 \mathrm{M}$ phosphate buffer, 0.1 $\mathrm{M} \mathrm{NaCl}$, at $\mathrm{pH}$ 7. The glucose solution was prepared every 7 days to allow mutarotation at room temperature before use. The Gox, type II had an activity of 39800 units $/ \mathrm{g}$ and was stored at $-5^{\circ} \mathrm{C}$. A $0.1 \mathrm{M}$ phosphate buffer at $\mathrm{pH} 7.0$ $\left(\mathrm{KH}_{2} \mathrm{PO}_{4} / \mathrm{K}_{2} \mathrm{HPO}_{4}\right)$ aqueous solution that contained $0.1 \mathrm{M} \mathrm{NaCl}$ was prepared by adding an aqueous solution $0.1 \mathrm{M} \mathrm{NaOH}$ to a solution of $0.2 \mathrm{M} \mathrm{KH}_{2} \mathrm{PO}_{4}$, adjusting the $\mathrm{pH}$ and adding solid $\mathrm{NaCl}$.

Electrochemical synthesis of copolymers and entrapment

Modified copolymer electrodes were prepared using potentiostatic oxidation of $15 \mathrm{ml}$ de-aerated aqueous solutions that contained $0.41 \mathrm{M}$ aniline, $0.20 \mathrm{M}$ aniline-2-sulfonic acid (or aniline-3-sulfonic acid) and $0.1 \mathrm{M} \mathrm{NaCl}$ as support electrolyte, at $875 \mathrm{mV}$ (vs $\mathrm{Ag} / \mathrm{AgCl}$ ) during 30 minutes on a platinum disc. Previously, the $\mathrm{pH}$ of dissolutions was adjusted at 4.90 by addition of aqueous solution $0.1 \mathrm{M} \mathrm{NaOH}$. Then, the electropolymerized films were 
washed with deionized water to remove unreacted monomer. GOx entrapment was performed under the same conditions, but adding $92 \mathrm{mg}\left(244 \mathrm{U} \mathrm{mL}^{-1}\right)$ of GOx to $15 \mathrm{ml}$ of co-monomeric solution and potentiostatically oxidizing on the platinum disc during 30 minutes. Then, the bio-electrodes were washed with deionized water to allow desorption of the weakly bounded enzyme (or monomer unreacted) from the surface.

Glucose Quantification

Stock b-D-glucose (0.1 M aqueous) was used in several glucose solution preparations, at $\mathrm{pH} 7.0$, at a concentration range of $2.0-30.0 \mathrm{mM}$ in $0.1 \mathrm{M}$ phosphate buffer $\left(\mathrm{KH}_{2} \mathrm{PO}_{4} / \mathrm{K}_{2} \mathrm{HPO}_{4}\right), 0,1 \mathrm{M} \mathrm{NaCl}$. The solutions were saturated with $\mathrm{O}_{2}$ and they were allowed to react during 10 minutes of out-stirring in the presence of bio-electrode ( $\mathrm{Pt} /$ copolymer/enzyme), and the generated hydrogen peroxide was quantified by cyclic voltammetry in the range of $-350-+1100$ $\mathrm{mV}$ at a sweep rate of $50 \mathrm{mV} / \mathrm{s}$ for four cycles, recording the highest current at $1100 \mathrm{mV}$ (vs Ag/AgCl).

\section{RESULTS AND DISCUSSION}

In order to study the bio-electrodes, Platinum disc electrode and copolymeric-electrodes were used as working electrodes for the oxidation of different $\mathrm{H}_{2} \mathrm{O}_{2}$ solutions, that contained $0.1 \mathrm{M}$ phosphate buffer and $0.1 \mathrm{M}$ $\mathrm{NaCl}$ at $\mathrm{pH}$ 7. To determine the oxidation and reduction potentials of hydrogen peroxide, it was used a cyclic voltammetry (CV). Figure 1 shows an oxidation peak located at $+700 \mathrm{mV}$ and a reduction peak located at $+198 \mathrm{mV}$ (versus $\mathrm{Ag} / \mathrm{AgCl}$ ). To compare both $\mathrm{CV}$ in the presence and absence of $\mathrm{H}_{2} \mathrm{O}_{2}$, we have been determined that the peak located at $+700 \mathrm{mV}$ correspond at the $\mathrm{H}_{2} \mathrm{O}_{2}$ oxidation. We have proved, with a platinum disc as working electrode, the quantification of a commercial hydrogen peroxide, using the controlled potential electrochemical method on the maximum peak of oxidation $(+700 \mathrm{mV}, 30$ $\mathrm{min})$. Thus, it was observed a lineal ratio between the peroxide concentration and the charge (Figure 2). However, using the same electrochemical method with copolymeric-electrodes (Pt/copolymers), peroxide quantification was not possible due to the electro-inactivity presented by the working electrodes in the oxidation zone. Nevertheless, using the highest current of the curve of four scans of the voltammogram, we determined an excellent linear relationship between the current and the peroxide concentration for both copolymericelectrodes. This behavior can be seen in Fig. 3. Besides, the two modifiedcopolymer electrodes have a lineal current response in respect to hydrogen peroxide concentration up to a limit of $20 \mathrm{mM}$. This value is the limit of the quantitative measurement of hydrogen peroxide, because the high local concentration of molecular oxygen formed on the interface solution-copolymer makes the peroxide oxidation process difficult. Moreover, the curve's slopes of modified-electrodes are lower at curve's slope of the Pt electrode due to charge transference difficult through of the polymeric material.

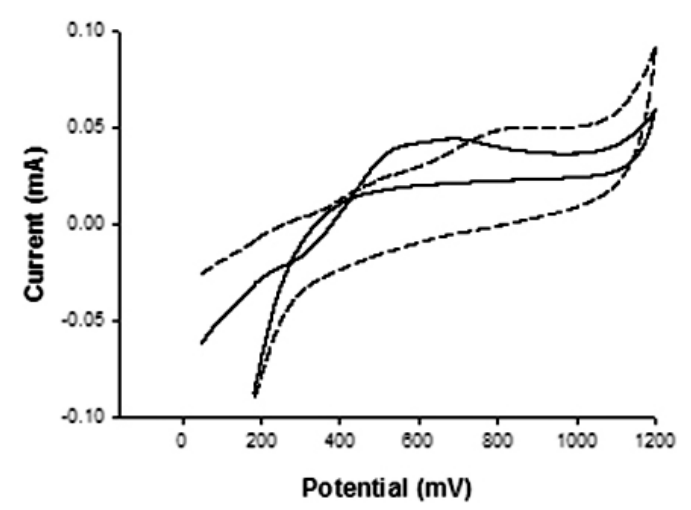

Figure 1: Voltammograms (CV) in the range -250 and $+1200 \mathrm{mV}$ (versus $\mathrm{Ag} / \mathrm{AgCl}$ ) of aqueous in $0.1 \mathrm{M}$ phosphate buffer, $0.1 \mathrm{M} \mathrm{NaCl}$ at $\mathrm{pH} 7$ using Platinum disc as working electrode with $1.17 \mathrm{mM} \mathrm{H}_{2} \mathrm{O}_{2}$ (continue line) and absence of $\mathrm{H}_{2} \mathrm{O}_{2}$ (broken line).

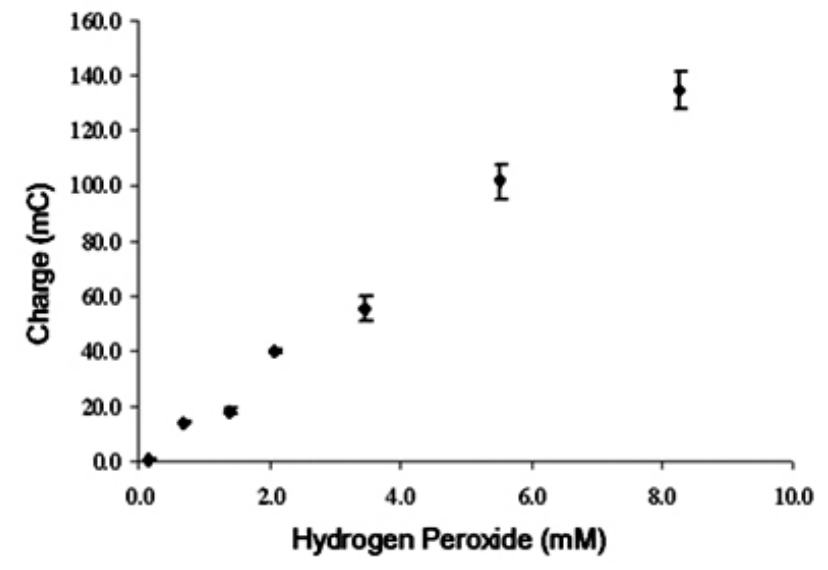

Figure 2: Electrolysis at controlled potential $(+700 \mathrm{mV}, 30 \mathrm{~min})$ of $\mathrm{H}_{2} \mathrm{O}_{2}$ in phosphate buffer, $0.1 \mathrm{M} \mathrm{NaCl}$ at $\mathrm{pH}$ 7. Platinum disc as working electrode.

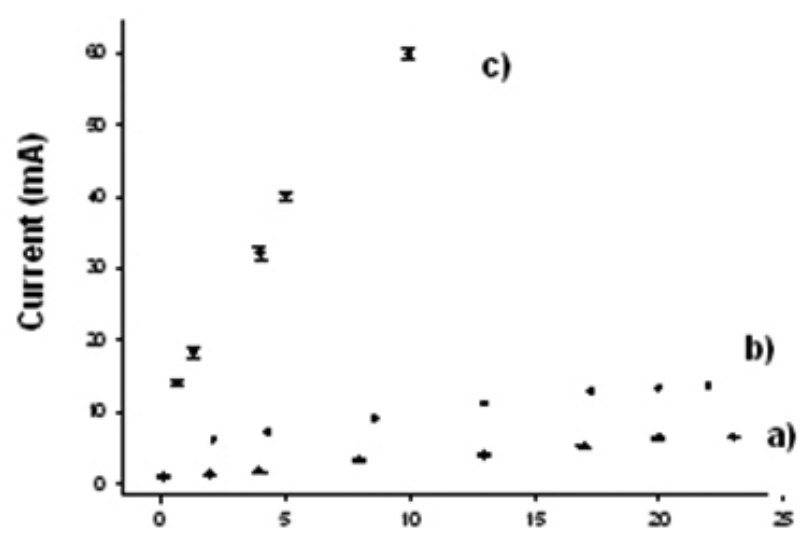

Hydrogen Peroxide (mM)

Figure 3: Quantification of $\mathrm{H}_{2} \mathrm{O}_{2}$ in phosphate buffer, $0.1 \mathrm{M} \mathrm{NaCl}$ at $\mathrm{pH}$ 7 by $\mathrm{CV}$ using as working electrodes: a) Pt/poly(aniline-co-aniline-2-sulfonic acid), curve's slope $0.259 ; \mathrm{r}=0.991, \mathrm{~b}$ ) Pt/poly(aniline-co-aniline-3-sulfonic acid), curve's slope $0.422 ; r=0.992$. Where $r$ is the linear regression, measured at $20 \mathrm{mM}$ and c) electrode of Platinum, curve's slope 5.54; $\mathrm{r}=0.975$.

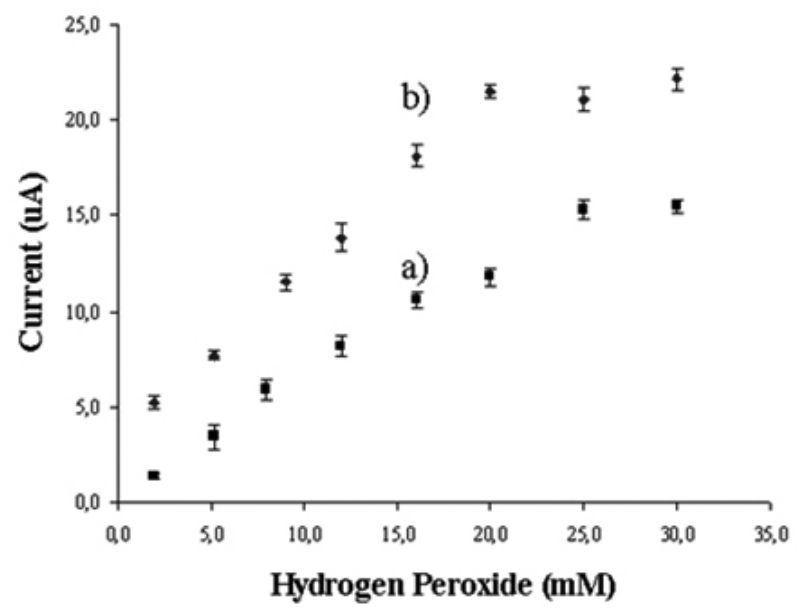

Figure 4: Quantification by CV of $\mathrm{H}_{2} \mathrm{O}_{2}$ obtained from D-glucose oxidation process, using: a) Pt/poly(aniline-co-aniline-2-sulfonic acid)/enzyme, curve's slope 0.596; $\mathrm{r}=0.991$, and b) Pt/poly(aniline-co-aniline-3-sulfonic acid)/ enzyme electrodes, curve's slope $0.919 ; \mathrm{r}=0.997$. 
Figure 4 shows the quantification of hydrogen peroxide obtained in the process of oxidation of D-glucose using an enzyme entrapped on the copolymeric electrodes. A linear relationship with low hydrogen peroxide concentration $(<20 \mathrm{mM})$ can be observed in the two curves.

In the polymerization process, the $\mathrm{pH}$ decreases in the proximity of the electrode and in this zone, the probability of enzyme deactivation could increase. However, using this type of copolymers, the enzyme remains activated.

For both electrodes, peroxide quantification was possible only for concentration of $20 \mathrm{mM}$ in the presence and absence of enzyme. The results suggest that the presence of the enzyme and the polymer nature are not the limiting factor in peroxide quantification at higher concentrations. Moreover, since the magnitude of the charge response of poly(aniline-co-aniline-3sulfonic acid) electrode is higher than the poly(aniline-co-aniline-2-sulfonic acid) electrode (in the presence and absence of enzyme), then, the poly(anilineco-aniline-3-sulfonic acid) electrode has higher electroactivity, possibly due to the higher content of benzenoid units in the copolymer in comparison with poly(aniline-co-aniline-2-sulfonic acid), (Figure 5 and Table 1).

According to the elemental analysis, the results indicate that the composition of the copolymers did not affect the linear range dependence between $\mathrm{H}_{2} \mathrm{O}_{2}$ (or D-glucose) concentration and the electrochemical response, but rather the magnitude of the current response.

Finally, the modified-electrodes displayed a fast time of current response, limited by the number of cycles of the CV, $232 \mathrm{~s}$, and enough stability to allow for the measurements after several days.

a)

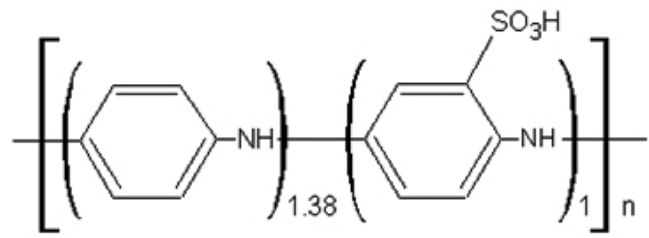

b)

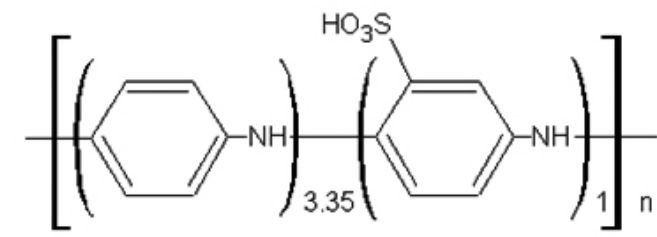

Figure 5: Proposed structures and copolymeric composition of a) Poly(aniline-co-aniline-2-sulfonic acid) and b) Poly(aniline-co-aniline-3sulfonic acid).

Table 1: Elemental analysis of copolymers and $\mathrm{mol} / \mathrm{mol}$ ratio between sulfur and nitrogen

\begin{tabular}{|c|c|c|c|c|c|}
\hline Polymer & $\mathbf{\%} \mathbf{~ N}$ & $\mathbf{\%} \mathbf{C}$ & $\begin{array}{c}\mathbf{\%} \\
\mathbf{H}\end{array}$ & $\mathbf{\% ~ S}$ & $\mathbf{S} / \mathbf{N}$ \\
\hline $\begin{array}{c}\text { Poly(aniline-co-aniline-2- } \\
\text { sulfonic acid) }\end{array}$ & 8,35 & 64,20 & 6,98 & 8,07 & $1 / 2.38$ \\
\hline $\begin{array}{c}\text { Poly(aniline-co-aniline-3- } \\
\text { sulfonic acid) }\end{array}$ & 10.90 & 56.93 & 3.89 & 5.74 & $1 / 4.35$ \\
\hline
\end{tabular}

The functional groups of the copolymers were recorded by FT-IR and UV-Vis spectroscopy. The more important bands in the FT-IR spectra are the $\mathrm{C}=\mathrm{N}$ stretching, localized at $1588 \mathrm{~cm}^{-1}$ (associated to quinoid groups), the $\mathrm{C}=\mathrm{C}$ stretching localized at $1495 \mathrm{~cm}^{-1}$ and $1501 \mathrm{~cm}^{-1}$ (associated to benzenoid groups), the $\mathrm{S}=\mathrm{O}$ stretching localized at $1147 \mathrm{~cm}^{-1}$ and $1150 \mathrm{~cm}^{-1}$ (associated to sulfonic acid groups), Figure 6. Furthermore, the quinoid and benzenoid groups were detected by UV-Vis absorption spectroscopy. In fact, the bands located at $280 \mathrm{~nm}$ and $560 \mathrm{~nm}$ were assigned at transitions $\pi-\pi^{*}$ (associated to benzenoid groups) and charge-transference transitions (associated to quinoiddiimine groups) respectively ${ }^{15}$.

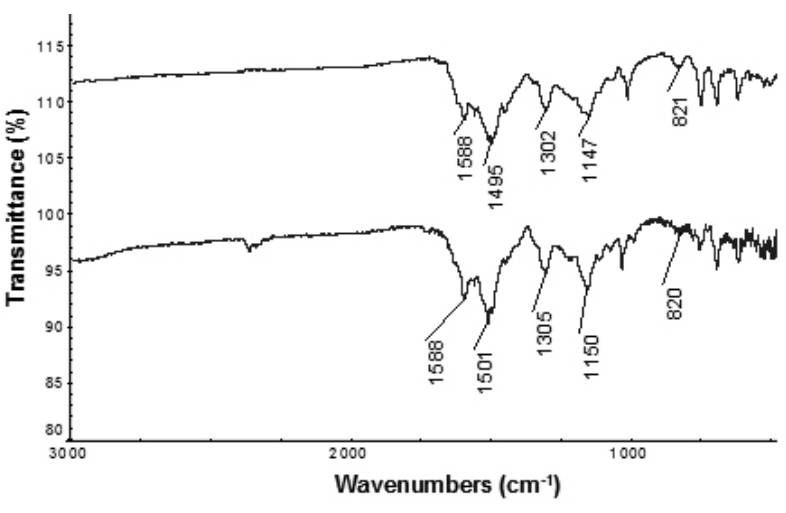

Figure 6: FT-IR spectra of Poly(aniline-co-aniline-2-sulfonic acid) (curve top), and poly(aniline-co-aniline-3-sulfonic acid).

Glucose-oxidase has an isoelectric point of $4.2^{16}$ and, therefore at $\mathrm{pH}$ over this value the enzyme is negatively charged. Since the copolymers are deposited on an oxidative process, it is favored the electrostatic interactions between these and the enzyme. Another favorable interaction is the dipoletype interaction between the sulfonic acid groups and the enzyme's functional groups. The aniline-sulfonated not homo-polymerized in the oxidative electrochemical process.

\section{CONCLUSIONS}

Aniline-2-sulfonic acid, aniline-3-sulfonic acid and aniline were used to prepare copolymers. The monomers properties allowed to use the entrapment method to incorporate enzyme in copolymers aniline derivatives. In the presence and absence of the enzyme, the copolymers were prepared by the electropolymerization process in aqueous media at $\mathrm{pH}$ 4.9. The enzyme was not de-naturalized in the electro-synthesis process.

Using the cyclic voltammetry, the biosensors have linear range dependence between the peroxide (or D-glucose) concentration and the electrochemical response, but only at low concentrations. Thus, the bio-electrodes can be used to quantify D-glucose or peroxide at concentrations lower than $20 \mathrm{mM}$.

The copolymeric-electrodes showed a good electroactivity at $\mathrm{pH} 7$ using $\mathrm{CV}$ method and they could be assayed for other enzymes.

\section{ACKNOWLEDGEMENTS}

The authors thank to DID-UACh (Grant S-200407, S-200620) and Fondecyt $\mathrm{N}^{\mathrm{o}} 1080119$ for the financial support for this work.

\section{REFERENCES}

1.- D.D. Borole, U. R. Kapadi, P. P. Mahulikar, D. G. Hundiwale, Polym. Adv. Technol. 15, 306, (2004).

2.- L. V. Lukahova, A. A. Karyakin, E. E. Karyakina, L. Gorton, Sens. Actuator B. 44, 356, (1997).

3.- C. Malitesta, F. Palmesano, L. Torsi, P. G. Zambonin, Anal. Chem. 62 , 2735, (1990).

4.- K. Ramanathan, S. S. Pandey, R. Kumar, A. Gulati, N. Murthy, B. D. Mahotra, J. Appl. Polym. Sci. 78, 662, (2000).

5.- M. Shaolin, H. Huaiguo, Sens. Actuator B Chem. 31, 155 (1996).

6.- K. Ramanathan, S. Annapoorni, B. D. Malhotra, Sens. Actuators B, 21, 165 (1994)

7.- A. A. Karyakin, M. Vuki, L. V. Lukachova, E. E. Karyakina, A. V. Orlov, Anal. Chem. 71, 2534 (1999).

8.- M. Trojanowicz, T. Krawczyski, O. Geschke, K. Cammann, Sens. Actuator B, 28, 191 (1995).

9.- D. T. Hoa, T. S. Kumar, N. S. Punekar, R. S. Srinivasa, R. Lai, A. Q. Contractor, Anal. Chem. 64, 2645, (1992).

10.- J. C. Cooper, E. A. H. Hall, Biosens. Bioelectron. 7, 473 (1992)

11.- T. Ohsaka, Y. Ohnuki, N. Oyama, G. Katayiri, K. Kamisako, J. Electroanal. Chem. 161, 399 (1984)

12.- N. Gospodinova, L. Terlemezyan, Prog. Polym. Sci. 23, 1443 (1998)

13.- Y. W. Park, J. S. Moon, M. K. Bak, J. I. Jin, Synth. Met. 29, 389 (1989).

14.- F. Fusalba, D. Bélanger, J. Phys. Chem. B, 103, 9044 (1999).

15.- A. Malinauskas, R. Holze, J. Appl. Polym. Sci. 73, 287 (1999)

16.- R. Bentley, P. D. Boyer, H. A. Lardy, The Enzymes, Academic Press, New York, 1973 